\title{
ESR Study of Degradation Mechanism Due to Charge Formation in Polymer Solar Cells
}

\author{
Kazuhiro Marumoto ${ }^{1,2, *}$, Dong Liu ${ }^{1}$, and Masaki Yabusaki ${ }^{1}$ \\ ${ }^{1}$ Division of Materials Science, University of Tsukuba, Tsukuba, Ibaraki 305-8573, Japan \\ ${ }^{2}$ Tsukuba Research Center for Interdisciplinary Materials Science (TIMS), University of Tsukuba, \\ Tsukuba, Ibaraki 305-8571, Japan \\ *marumoto@ims.tsukuba.ac.jp
}

\begin{abstract}
The degradation mechanism of polymer solar cells containing a lithium-fluoride (LiF) buffer layer created by a thermal annealing process at different temperatures was studied using an electron spin resonance (ESR) and current-voltage characteristics. The device structure was indium-tin-oxide (ITO)/poly(3,4-ethylenedioxythiophene): poly(4-styrenesulfonate) (PEDOT:PSS)/poly(3-hexylthiophene):phenyl-C 61 -butyric acid methyl ester (P3HT:PCBM)/LiF/Al. When the post-annealing temperature increased, the performance of the cells decreased and the ESR signal from PCBM radical anions was enhanced dramatically. The formation of a greater number of anions enhanced the electron scattering and caused an energy-level shift at the interface. These effects led to degradation in the device performance.
\end{abstract}

Keywords: electron spin resonance (ESR), polymer solar cells, lithium-fluoride (LiF) buffer layer, thermal annealing

\section{Introduction}

Organic thin-film solar cells have attracted tremendous interest as a future technology for renewable energy because of their printable and flexible device structure, light weight, and low-cost production [1-3]. One of the most widely studied organic thin-film solar cells employs an active layer of blend films with a poly(3-hexylthiophene) (P3HT) electron donor and a phenyl- $\mathrm{C}_{61}$-butyric acid methyl ester (PCBM) electron acceptor. The performance of solar cells has been improved using a variety of methods, such as the insertion of a lithium-fluoride (LiF) buffer layer [4-6], thermal annealing [7-11], solvent annealing [12,13], and the use of mixed solvents [14]. In particular, the effects of LiF insertion and thermal annealing have drastically improved the performance such as power-conversion efficiency (PCE) [15].

The most important effect of $\mathrm{LiF}$ is related to its function as a dipole layer [4,5]. The LiF layer imparts a significant vacuum-level offset, which results in a reduction in the interfacial energy barriers $[4,5]$. LiF is also utilized to block holes and diminish electron-hole recombination near $\mathrm{Al}$ electrodes [6]. Thermal annealing typically consists of two stages: pre-annealing, which is used on films prior to the deposition of metal electrodes, and post-annealing, which is used for fabricated devices after the deposition of metal electrodes [16]. These two annealing stages have different effects for different device structures with and without LiF buffer layers. Pre-annealing has been reported to improve the efficiency of solar cells containing LiF [16], whereas post-annealing has been reported to improve the efficiency of solar cells that do not contain LiF [7-9,11]. Li et al. have reported that the LiF buffer layer is modified by the post-annealing [16]. However, detailed studies of the effects of annealing on device 
performance using microscopic characterization had not yet been performed.

Electron spin resonance (ESR) is a promising method for microscopic characterization because it is highly sensitive and can be utilized to investigate organic materials and devices at the molecular level [17-20]. We previously studied the effects of thermal annealing on device performance using ESR [21]. However, the detailed discussion on the effects of different annealing temperatures using the device performance and ESR have not yet been reported.

Here we report the detailed discussion on the effects of annealing temperatures using the device performance and ESR. The utilized device structure was indium-tin-oxide (ITO)/poly(3,4-ethylenedioxythiophene):poly( 4-styrenesulfonat) (PEDOT:PSS)/P3HT: $\mathrm{PCBM} / \mathrm{LiF} / \mathrm{Al}$. The results of current density-voltage $(J-V)$ characteristics and ESR using different annealing temperatures are presented. The number of radical anions on the PCBM was enhanced remarkably by the post-annealing process, which indicated the formation of $\mathrm{PCBM}^{-} \mathrm{Li}^{+}$charge-transfer complexes. This enhancement was caused by the surface segregation of PCBM and by the dissociation of $\mathrm{LiF}$ at the Al interface by the post-annealing process [21]. The radical anions formed on the PCBM inhibit electron transport in the PCBM molecules [22], which degrades device performance. The ESR results are compared with the device characteristics at different post-annealing temperatures in terms of the formation of PCBM radical anions.

\section{Experimental}

\subsection{Device structures}

The structure of the polymer solar cells was as follows: ITO/PEDOT:PSS $\quad(\approx 40$ $\mathrm{nm}) / \mathrm{P} 3 \mathrm{HT}: \mathrm{PCBM}(\approx 120 \mathrm{~nm}) / \mathrm{LiF}(\approx 1 \mathrm{~nm}$ or none)/Al $(80 \mathrm{~nm})$. The solar cells with active areas of $2 \mathrm{~mm} \times 2 \mathrm{~mm}$ were fabricated on a $20 \mathrm{~mm} \times 20 \mathrm{~mm}$ glass substrate for the $J-V$ characteristics and those of $2 \mathrm{~mm} \times 10 \mathrm{~mm}$ were fabricated on a $3 \mathrm{~mm} \times 20 \mathrm{~mm}$ quartz substrate for the ESR measurements $[19,20]$.

\subsection{Device fabrication}

Solutions of P3HT and PCBM $(1: 1 \mathrm{w} / \mathrm{w})$ were dissolved in $o$-dichlorobenzene (3.0 $\mathrm{wt} \%$ ) and stirred for $15 \mathrm{~h}$ at $40^{\circ} \mathrm{C}$. They were then spin-coated onto the PEDOT:PSS films. The pre-annealing is defined as the annealing of the fabricated layer at $110^{\circ} \mathrm{C}$ for $10 \mathrm{~min}$ before the electrode was deposited. $\mathrm{LiF} / \mathrm{Al}$ or Al layers were deposited onto the P3HT:PCBM layer to form the electrode using a vacuum-sublimation technique at pressures less than $1 \times 10^{-4} \mathrm{~Pa}$. The post-annealing is defined as the annealing of the fabricated device at $110^{\circ} \mathrm{C}$ for $10 \mathrm{~min}$ after the electrode was deposited. All thermal annealing treatments were performed in a nitrogen-filled glove box $\left(<0.2 \mathrm{ppm} \mathrm{O}_{2},<\right.$ $0.6 \mathrm{ppm} \mathrm{H}_{2} \mathrm{O}$ ).

\subsection{Measurement}

The $J-V$ characteristics were evaluated using an Agilent Technology B1500A semiconductor device analyzer under simulated solar irradiation (AM 1.5G) with a $100 \mathrm{~mW} \mathrm{~cm}^{-2}$ intensity at room temperature under an Ar atmosphere. The ESR measurements were performed using a JEOL RESONANCE JES-FA200 X-band spectrometer in the dark at room temperature under a $\mathrm{N}_{2}$ atmosphere. The number of spins and the $g$ factor of the ESR signal were calibrated using a standard $\mathrm{Mn}^{2+}$ marker sample.

\section{Results and Discussion}

\section{1. $J-V$ characteristics}

The $J-V$ characteristics for solar cells with LiF that were fabricated using different post-annealing temperatures are shown in Figure 1. The device performance is summarized in Table 1. For the performance of the solar cell with LiF, the 'Unannealed' device exhibited the best performance, with a PCE of $3.58 \%$. The PCE monotonically decreased as the post-annealing temperature increased and showed $2.46 \%$ for the $' 160^{\circ} \mathrm{C}$ annealed' device. Therefore, the post-annealing of devices with LiF negatively affects the photovoltaic properties of the devices [16]. As shown later, the reason for the decrease can be attributed to the increase in the number of PCBM radical anions at higher temperatures. No change in the spectral shape of the incident photon-to-current conversion efficiency 


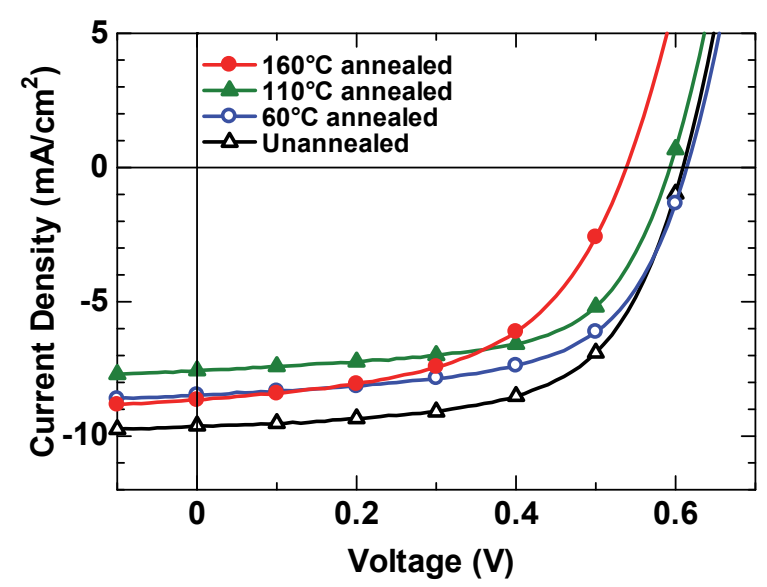

Fig. 1. $J-V$ characteristics of ITO/PEDOT:PSS/ $\mathrm{P} 3 \mathrm{HT}: \mathrm{PCBM} / \mathrm{LiF} / \mathrm{Al}$ subjected to various post-annealing temperatures.

(IPCE) was observed after thermal annealing, which means the molecules did not degrade.

\subsection{ESR study of devices}

The ESR signals for the device have been measured to investigate the reaction between $\mathrm{LiF}$ and the organic molecules. Figure 2 shows the ESR signals for ITO/PEDOT:PSS/P3HT:PCBM/LiF/Al with and without post-annealing at $110^{\circ} \mathrm{C}$. The vertical axis is plotted using units of peak-to-peak ESR intensity of the ESR signal of a standard $\mathrm{Mn}^{2+}$ mark sample, $I_{\mathrm{Mn}}$. ESR signals from the PEDOT:PSS $(g=2.003)$, the P3HT $(g=2.002)$, and the PCBM $(g=1.999)$ were observed for the 'Unannealed' device [21]. The $g$ factor of 2.002 is consistent with

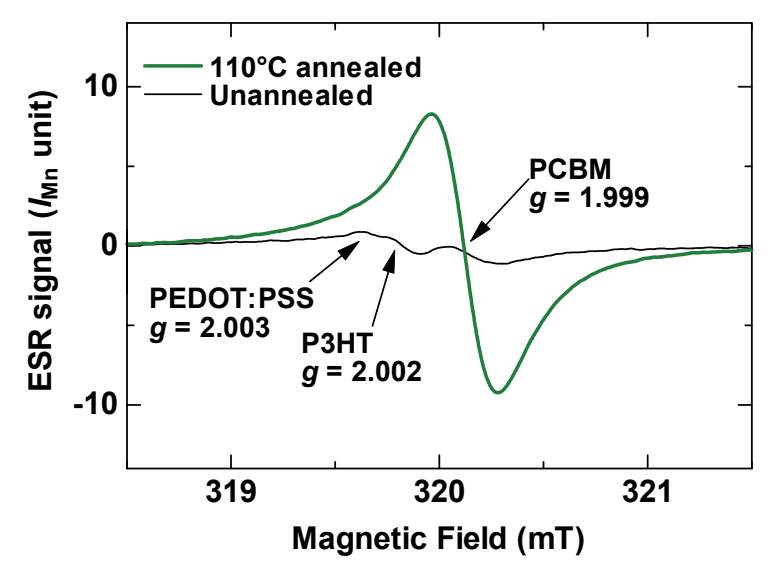

Fig. 2. ESR signals of ITO/PEDOT:PSS/ P3HT:PCBM/LiF/Al with and without post-annealing treatment under open-circuit conditions.
Table 1. Performance of polymer solar cells fabricated with LiF buffer layers and subjected to various post-annealing temperatures.

\begin{tabular}{ccccc}
\hline \hline $\begin{array}{c}\text { Post-annealing } \\
\text { temperature }\end{array}$ & $\begin{array}{c}J_{\mathrm{sc}} \\
\left(\mathrm{mA} / \mathrm{cm}^{2}\right)\end{array}$ & $\begin{array}{c}V_{\mathrm{oc}} \\
(\mathrm{mV})\end{array}$ & FF & $\begin{array}{c}\text { PCE } \\
(\%)\end{array}$ \\
\hline Unannealed & 9.61 & 610 & 0.61 & 3.58 \\
$60^{\circ} \mathrm{C}$ & 8.47 & 610 & 0.61 & 3.14 \\
$110^{\circ} \mathrm{C}$ & 7.56 & 590 & 0.61 & 2.75 \\
$160^{\circ} \mathrm{C}$ & 8.65 & 540 & 0.53 & 2.46 \\
\hline \hline
\end{tabular}

that of radical cations (positive polarons) on P3HT in organic field-effect devices $[23,24]$. The ESR signal of the PEDOT:PSS and the P3HT overlapped with each other because of their similar $g$ factors $[19,20]$.

The ESR signal at $g=1.999$ corresponds to the PCBM radical anions [23,25-27]. The observation of the PCBM signal can most likely be ascribed to the formation of $\mathrm{PCBM}^{-} \mathrm{Li}^{+}$charge-transfer complexes. In a previous study, the interaction between $\mathrm{LiF}$ and $\mathrm{C}_{60}$ followed by the deposition of $\mathrm{Al}$ was reported to produce the ESR signal of $\mathrm{C}_{60}$ radical anions, which is strongly suggested to be due to $\mathrm{C}_{60}{ }^{-} \mathrm{Li}^{+}$charge-transfer complexes [28]. Surprisingly, in the case of the post-annealing, we observed a remarkable increase in the ESR intensity from PCBM radical anions. This result indicates that the number of PCBM radical anions, $N_{\text {spin, }}$ increases remarkably due to post-annealing. As shown later, the $N_{\text {spin }}$ increased showing a one order of magnitude larger value by the post-annealing; this dramatic enhancement was nearly identical to that observed for quartz/P3HT:PCBM/LiF/Al. Therefore, by investigating the same device with and without post-annealing, we confirmed the relation between the increase in the ESR signal and the degradation of the device performance caused by the formation of radical anions on the PCBM during post-annealing.

The stability of the PCBM radical anions was studied by applying a reverse bias of $-700 \mathrm{mV}$ to the device for $3 \mathrm{~h}$ after post-annealing. No change in $N_{\text {spin }}$ was observed, which indicates that the PCBM radical anions are stable, most likely due to the formation of $\mathrm{PCBM}^{-} \mathrm{Li}^{+}$complexes rather than due to electron trappings in the PCBM. Notably, the ESR signal for radical anions on PCBM cannot usually be observed at room temperature because of the rapid spin relaxation of the fullerene electrons at room temperature $[20,23,27]$. 


\subsection{ESR study of layered thin films}

To investigate the mechanisms for the formation of PCBM radical anions by post-annealing, an ESR study on the samples of quartz/P3HT:PCBM/LiF/Al for different post-annealing temperatures was performed. The ESR signal from PCBM radical anions increased with increasing post-annealing temperature, as shown in Fig. 3. This result indicates that the surface segregation of PCBM in addition to the dissociation of LiF at the $\mathrm{LiF} / \mathrm{Al}$ interface are further enhanced at higher annealing temperatures [21].

\subsection{Mechanism of performance degradation}

The mechanism of the performance degradation is discussed using the ESR results. The ratio of the $\mathrm{LiF}$ dissociation was examined using the $N_{\text {spin }}$. Table 2 shows the dependence of $N_{\text {spin }}$ and the ratio of LiF for PCBM anion formation on post-annealing temperatures. The $N_{\text {spin }}$ was evaluated from the ESR signals shown in Fig. 3. The $N_{\text {spin }}$ monotonically increases as the post-annealing temperature increases. The $N_{\text {spin }}$ after post-annealing at $110^{\circ} \mathrm{C}$ was $1.27 \times 10^{14}$. On the basis of the volume of the LiF layer $(3 \times$ $10^{-8} \mathrm{~cm}^{3}$ ), the number of $\mathrm{Li}$ atoms in the deposited LiF layer was $1.84 \times 10^{15}$. Thus, we found that only $6.2 \%$ of the $\mathrm{Li}$ atoms contributed to the additional formation of the PCBM radical anions during post-annealing at $110^{\circ} \mathrm{C}$. This result indicates that the thermal annealing process did not completely destroy the $\mathrm{LiF}$ function at post-annealing temperatures up to $110^{\circ} \mathrm{C}$. Thus, the decrease in $J_{\text {sc }}$ at post-annealing temperatures up to

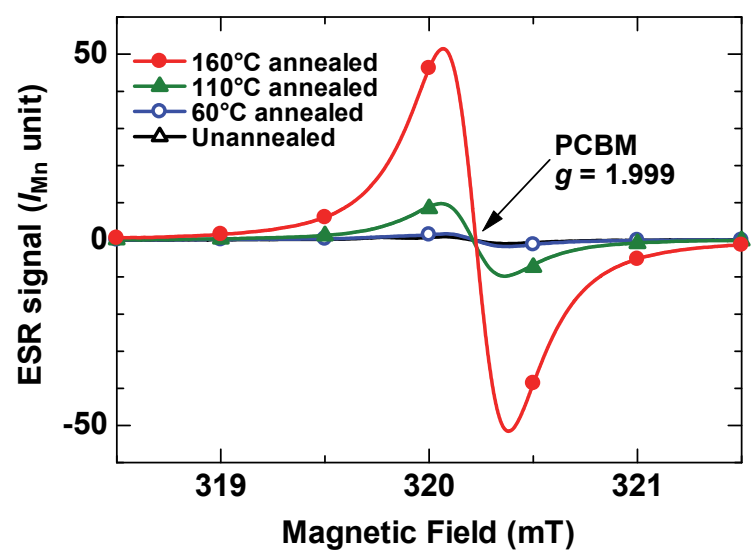

Fig. 3. ESR signals of quartz/P3HT:PCBM/LiF/Al post-annealed at various temperatures.
Table 2. Dependence of $N_{\text {spin }}$ and the ratio of LiF for PCBM anion formation on post-annealing temperatures.

\begin{tabular}{ccc}
\hline \hline $\begin{array}{c}\text { Post-annealing } \\
\text { temperature }\end{array}$ & $N_{\text {spin }}$ & $\begin{array}{c}\text { Ratio of LiF for } \\
\text { PCBM anion } \\
\text { formation }\end{array}$ \\
\hline Unannealed & $1.19 \times 10^{13}$ & $0.7 \%$ \\
$60^{\circ} \mathrm{C}$ & $1.92 \times 10^{13}$ & $1.0 \%$ \\
$110^{\circ} \mathrm{C}$ & $1.27 \times 10^{14}$ & $6.9 \%$ \\
$160^{\circ} \mathrm{C}$ & $6.03 \times 10^{14}$ & $33 \%$ \\
\hline
\end{tabular}

$110^{\circ} \mathrm{C}$ cannot be explained by the loss of the $\mathrm{LiF}$ function due to the complete dissociation of the LiF layer. For another mechanism for the decrease in $J_{\text {sc }}$ at post-annealing temperatures up to $110^{\circ} \mathrm{C}$, electron scattering by PCBM anion formation have been discussed [21]. Harada et al. have reported that the mobility of $\mathrm{n}$-doped $\mathrm{C}_{60}$ decreases with increasing doping density because of the charge-carrier scattering by $\mathrm{C}_{60}$ anions [22]. On the basis of the similar characteristics of $\mathrm{C}_{60}$ and PCBM, the mobility can be reasonably inferred to decrease with increasing such electron scattering. Anion formation decreases $J_{\mathrm{sc}}$ and concomitantly decreases $V_{\text {oc }}$ [11]. Anion formation should also decrease $V_{\text {oc }}$ because of the shift in energy levels at the interfaces $[19,20]$. The expected decrease in $V_{\text {oc }}$ was, indeed, observed (see Fig. 1 and Table 1). When the post-annealing temperature increases to $160^{\circ} \mathrm{C}$, the $N_{\text {spin }}$ increases to $6.03 \times 10^{14}$ which corresponds to the ratio of the $\mathrm{LiF}$ dissociation of $33 \%$ (see Table 2). Such large $N_{\text {spin }}$ causes the decrease in $V_{\text {oc }}$ down to 540 $\mathrm{mV}$ for the ' $160^{\circ} \mathrm{C}$ annealed' device from 610 $\mathrm{mV}$ for the 'Unannealed' device.

\section{Conclusion}

An ESR study of organic solar cells with P3HT:PCBM blend films subjected to different post-annealing temperatures has been performed to investigate the degradation mechanism of cells containing a LiF buffer layer after post-annealing. An ESR signal from PCBM radical anions in dark conditions was clearly observed, which resulted from the formation of $\mathrm{PCBM}^{-} \mathrm{Li}^{+}$complexes at the $\mathrm{PCBM} / \mathrm{LiF} / \mathrm{Al}$ interface. The number of PCBM anions was remarkably enhanced by the post-annealing, which is reasonably explained by the surface segregation of 
PCBM and the dissociation of $\mathrm{LiF}$ at the interface. The formation of PCBM radical anions caused the performance of the devices to degrade because of electron scattering and the energy-level shift at the interface those were induced by the formation of the PCBM anions. Thus, ESR is an extremely effective method for investigating the microscopic degradation mechanisms of organic solar cells because it can detect charge formation in devices during the various device fabrication steps.

\section{Acknowledgements}

This work was partly supported by a Grant-in-Aid for Scientific Research (24560004) from the Japan Society for the Promotion of Science (JSPS) and by JST, PRESTO.

\section{References}

1. C. J. Brabec, V. Dyakonov, J. Parisi, and N. S. Sariciftci (Eds.), Organic Photovoltaics: Concepts and Realization, vol. 60, Springer, Berlin, Germany (2003).

2. S. Gunes, H. Neugebauer, and N. S. Sariciftci, Chem. Rev., 107 (2007) 1324.

3. T. M. Clarke and J. R. Durrant, Chem. Rev., 110 (2010) 6736.

4. C. J. Brabec, S. E. Shaheen, C. Winder, N. S. Sariciftci, and P. Denk, Appl. Phys. Lett., 80 (2002) 1288.

5. E. Ahlswede, J. Hanisch, and M. Powalla, Appl. Phys. Lett., 90 (2007) 163504.

6. B.-W. Yang, M.-Y. Tsai, W.-H. Chang, J.-S. Chen, S. L.-C. Hsu, and W.-Y. Chou, J. Phys. Chem. C, 117 (2013) 14472.

7. W. Ma, C. Yang, X. Gong, K. Lee, and A. J. Heeger, Adv. Funct. Mater., 15 (2005) 1617.

8. T. Erb, U. Zhokhavets, G. Gobsch, S. Raleva, B. Stuhn, P. Schilinsky, C. Waldauf, and C. J. Brabec, Adv. Funct. Mater., 15 (2005) 1193.

9. T. M. Clarke, A. M. Ballantyne, J. Nelson, D. D. C. Bradley, and J. R. Durrant, $A d v$. Funct. Mater., 18 (2008) 4029.

10. Y. Kim, A. M. Ballantyne, J. Nelson, and D. D. C. Bradley, Org. Electron., 10 (2009) 205.

11. A. Orimo, K. Masuda, S. Honda, H. Benten, S. Ito, H. Ohkita, and H. Tsuji,
Appl. Phys. Lett., 96 (2010) 043305.

12. S. Miller, G. Fanchini, Y.-Y. Lin, C. Li, C.-W. Chen, W.-F. Sub, and M. Chhowalla, J. Mater. Chem., 18 (2008) 306.

13. J. H. Park, J. S. Kim, J. H. Lee, W. H. Lee, and K. Cho, J. Phys. Chem. C, 113 (2009) 17579.

14. Y. Yao, J. H. Hou, Z. Xu, G. Li, and Y. Yang, Adv. Funct. Mater., 18 (2008) 1783.

15. S. K. Jonsson, W. R. Salaneck, and M. Fahlman, J. Appl. Phys., 98 (2005) 014901

16. F. Li, J. Zhao, K. Yao, and Y. Chen, Chem. Phys. Lett., 553 (2012) 36.

17. K. Marumoto, M. Kato, H. Kondo, S Kuroda, N. C. Greenham, R. H. Friend, Y. Shimoi, and S. Abe, Phys. Rev. B, 79 (2009) 245204.

18. M. Tsuji, Y. Takahashi, Y. Sakurai, Y. Yomogida, T. Takenobu, Y. Iwasa, and K. Marumoto, Appl. Phys. Lett., 102 (2013) 133301

19. K. Marumoto, T. Fujimori, M. Ito, and T. Mori, Adv. Energy Mater., 2 (2012) 591.

20. T. Nagamori and K. Marumoto, $A d v$. Mater., 25 (2013) 2362.

21. D. Liu, T. Nagamori, M. Yabusaki, T. Yasuda, L. Han, and K. Marumoto, Appl. Phys. Lett., 104 (2014) 243903.

22. K. Harada, F. Li, B. Maenning, M. Pfeiffer, and K. Leo, Appl. Phys. Lett., 91 (2007) 092118.

23. K. Marumoto, T. Sakamoto, S. Watanabe, H. Ito, and S. Kuroda, Jpn. J. Appl. Phys., 46 (2007) L1191.

24. S. Watanabe, H. Tanaka, S. Kuroda, A Toda, S. Nagano, T. Seki, A. Kimoto, and J. Abe, Appl. Phys. Lett., 96 (2010) 173302 .

25. J. De Ceuster, E. Goovaerts, A. Bouwen, J. C. Hummelen, and V. Dyakonov, Phys. Rev. B, 64 (2001) 195206.

26. O. G. Poluektov, S. Filippone, N. Martín, A. Sperlich, C. Deibel, and V. Dyakonov, J. Phys. Chem. B, 114 (2010) 14426.

27. A. Aguirre, S. C. J. Meskers, R. A. J. Janssen, and H.-J. Egelhaaf, Org. Electron., 12 (2011) 1657.

28. E. D. Glowacki, K. L. Marshall, C. W. Tang, and N. S. Sariciftci, Appl. Phys. Lett., 99 (2011) 043305. 